\title{
Queimadas em áreas do Cerrado brasileiro
}

As queimadas têm causado prejuízos aos elementos da paisagem, destruição da fauna e flora, além da deterioração da fertilidade do solo. $\mathrm{O}$ objetivo do presente trabalho é a detecção e quantificação de extensas áreas atingidas por eventos de queimadas através de sensores óticos, verificando a reincidência de queimadas em localidades do Cerrado a partir de imagens de sensoriamento remoto. A área de estudo foi a microrregião de Barreiras-Bahia, que possui aproximadamente $53.000 \mathrm{~km}^{2}$, sendo constituída por sete municípios: Barreiras, Luís Eduardo Magalhães, São Desidério, Formosa do Rio Preto, Riachão das Neves, Baianópolis e Catolândia. Para a realização do trabalho foram utilizados dados de foco de calor adquiridos no portal do Instituto Nacional de Pesquisas Espaciais (INPE), oriundos do satélite NOAA-19; e os dados de pluviometria foram disponibilizados pela Agência Nacional de Águas (ANA) e Instituto Nacional de Meteorologia (INMET). Para analisar a densidade dos focos de calor foi utilizado o método de densidade de Kernel, e foi analisada a sua relação com a precipitação entre 2015 a 2019 . Com os dados referentes a precipitação anual média na microrregião de Barreiras, foi utilizado o método do Inverso da Distância Ponderada (IDW) para gerar mapas de índices pluviométricos. Conclui-se que quando comparadas as ocorrências de focos de calor com a média anual precipitada, em cada ano, é possível indicar que a quantidade de precipitação registrada na região, mesmo que de forma assimétrica, pode ter influenciado na ocorrência de focos de incêndio. Embora que quando comparadas a distribuição espacial dos focos de calor com a distribuição espacial da precipitação, não se observa clara relação entre ambos, já que a distribuição temporal da precipitação pode influenciar nesse processo, além da ocorrência de queimadas por práticas intencionais, acidentais ou criminosas.

Palavras-chave: Queimadas; Cerrado; Pluviometria; Oeste Baiano.

\section{Burns in areas of the Brazilian Cerrado}

The fires have caused damage to landscape elements, destruction of fauna and flora, in addition to deteriorating soil fertility. The objective of the present work is the detection and quantification of extensive areas affected by fire events through optical sensors, verifying the recurrence of fires in Cerrado locations from remote sensing images. The study area was the micro-region of Barreiras-Bahia, which has approximately 53,000 $\mathrm{km}^{2}$, comprising seven municipalities: Barreiras, Luís Eduardo Magalhães, São Desidério, Formosa do Rio Preto, Riachão das Neves, Baianópolis and Catolândia In order to carry out the work, the heat focus data acquired at the website of the National Institute for Space Research (INPE) were used, from the NOAA-19 satellite; rainfall data were made available by the National Water Agency (ANA) and the National Meteorological Institute (INMET). To analyze the density of the heat sources, the Kernel density method was used, and its relationship with precipitation between 2015 and 2019 was analyzed. With the data referring to the average annual precipitation in the Barreiras microregion, the Inverse method was used Weighted Distance (IDW) to generate rainfall index maps. It is concluded that when comparing the occurrences of heat sources with the annual average precipitated, in each year, it is possible to indicate that the amount of precipitation registered in the region, even if asymmetrically, may have influenced the occurrence of fire sources. Although when comparing the spatial distribution of the heat sources with the spatial distribution of precipitation, there is no clear relationship between both, since the temporal distribution of precipitation can influence this process, in addition to the occurrence of fires by intentional, accidental or criminal practices.

Keywords: Burnings; Thick; Rainfall; West of Bahia.

Topic: Desenvolvimento, Sustentabilidade e Meio Ambiente

Reviewed anonymously in the process of blind peer
Received: 04/12/2020

Approved: 21/12/2020
Francisco Rubens Feitosa Júnior (iD

Universidade Federal do Oeste da Bahia, Brasil

http://lattes.cnpq.br/1603533849627421

http://orcid.org/0000-0001-7793-2138

rubensir21@hotmail.com

Ranieldo Barreiras Barbosa Souza (iD

Universidade Federal do Oeste da Bahia, Brasil

http://lattes.cnpq.br/2995123274670779

http://orcid.org/0000-0001-6947-2872

ranieldosouza89@gmail.com

Tâmara Andressa Pires Cedro (iD

Universidade Federal do Oeste da Bahia, Brasil

http://lattes.cnpq.br/9233640726506470

http://orcid.org/0000-0002-7225-9578

tamara drica@hotmail.com

DOI: 10.6008/CBPC2179-6858.2020.007.0046

\author{
Rayan Araújo Valério (iD \\ Universidade Federal do Oeste da Bahia, Brasil \\ http://lattes.cnpq.br/7010730874024371 \\ http://orcid.org/0000-0001-6862-8134 \\ rayanaraujov@gmail.com \\ Edimar Souza Dias \\ Universidade Federal do Oeste da Bahia, Brasil \\ http://lattes.cnpq.br/7322906269065751 \\ http://orcid.org/0000-0003-1388-5357 \\ esd.geotecnologias@gmail.com \\ José Yure Gomes dos Santos (iD) \\ Universidade Federal do Rio Grande do Norte, Brasil \\ http://lattes.cnpq.br/3612232712577710 \\ http://orcid.org/0000-0001-9840-8132 \\ joseyure@ceres.ufrn.br
}

\section{Referencing this:}

FEITOSA JÚNIOR, F. R.; SOUZA, R. B. B.; CEDRO, T. A. P.; VALÉRIO, R. A.; DIAS, E. S.; SANTOS, J. Y. G.. Queimadas em áreas do Cerrado brasileiro. Revista Ibero Americana de Ciências Ambientais, v.11, n.7, p.587-601, 2020. DOI: http://doi.org/10.6008/CBPC2179-

$\underline{6858.2020 .007 .0046}$ 


\section{INTRODUÇÃO}

O Cerrado é o segundo maior bioma da América do Sul, com área estimada em 2.036 .448 km, o que representa aproximadamente $22 \%$ do território brasileiro (MMA, 2014). O bioma Cerrado é rico em termos de biodiversidade e corre o risco de desaparecer se continuarem em seus territórios as formas atuais de desmatamento e transformação da vegetação natural em áreas antropizadas.

Segundo Strassbourg et al. (2017), o bioma Cerrado pode atingir seu colapso em decorrência das atividades humanas, pois as atuais praticas vão ocasionar até 2050 uma redução entre 31 e 34\% deste bioma, o que repercutirá na extinção aproximada de 480 espécies vegetais e um impacto em todos os ecossistemas mundiais.

Os registros de incêndios mundiais colocam em evidencias as áreas tropicais, onde as queimadas ocorrem com mais frequência e causam sérios problemas a muitos ecossistemas, prejudicando a saúde de bilhões de pessoas e a economia. Em virtude disso torna-se imprescindível estudos em ambientes como o Cerrado para compreender os impactos do fogo em ambientes tropicais (COCHRANE, 2009).

$\mathrm{O}$ crescimento anual de áreas cultivadas e de pastagens tem sido observado no bioma Cerrado nas últimas décadas (VACCHIANO et al., 2019; GONÇALVES et al., 2019). O bioma está sofrendo um processo de modificação de seu território em virtude da conversão das áreas nativas em áreas antropizadas (ALENCAR et al., 2020).

No Brasil, as queimadas estão relacionadas ao desmatamento (DALDEGAN et al., 2019; GONINO et al., 2019). O fogo é um instrumento de manejo utilizado em aproximadamente $50 \%$ dos ecossistemas terrestres sendo de origem natural ou criminosa, podendo gerar grandes desastres ambientais (LIU et al., 2016; DINTWE et al., 2017; CLEMENTE et al., 2017; FORKEL et al., 2017).

As utilizações de queimadas para o manejo de pastagem diminuem as pragas e removem os remanescentes agrícolas, porém pode tomar magnitudes desastrosas, atingindo a vegetação nativa, matando animais silvestres, espécies endêmicas e pode chegar em áreas urbanas (COCHRANE, 2009), pois fatores abióticos e bióticos, como o clima, topografia e a composição da comunidade vegetal podem intensificar as queimadas (CANSLER et al., 2014; KEELEY et al., 2016; ZYLSTRA et al., 2016).

Outro sério problema decorrente das queimadas é o favorecimento de alguns predadores invasores, que com a remoção da vegetação nativa, colocam em risco espécies endêmicas (SALO et al., 2007; LEAHY et al. 2016), podendo ocasionar diminuição e até extinção das populações de espécies nativas (HRADSKY et al., 2019).

O cerrado foi responsável pela emissão de aproximadamente 189 milhões de toneladas de $\mathrm{CO}^{2} \mathrm{em}$ 1990 e 379 milhões de toneladas em 2005 (MMA, 2011). Como é sabido as queimadas podem modificar o balanço hidrológico e reduzir a quantidade de precipitação (ANDREAE et al., 2001; COCHRANE, 2009), em decorrência disso mapas da gravidade do fogo podem facilitar uma melhor compreensão dos efeitos ecológicos e o comportamento dos incêndios (COLLINS et al., 2014; COPPOLETTA et al., 2016) e possibilitar estratégias para minimização do seus impactos, sendo um recurso vital para a pesquisa ecológica e de 
mudanças climáticas (FLANNIGAN et al., 2009; KEELEY et al., 2016).

A região Oeste da Bahia, que tem Barreiras como o seu principal município, é uma região característica de bioma Cerrado e que enfrentou nas últimas décadas um intenso processo de alteração no seu uso e ocupação do solo para o desenvolvimento da agricultura de grãos em larga escala (SANTOS, 1996; SANTOS et al., 2014).

Com esse intenso processo de alteração no seu uso e ocupação do solo para atividades agrícolas e expansão de centros urbanos, a ocorrência de queimada se torna recorrente em decorrência da sua utilização para atividades agrícolas, eventos acidentais e naturais, já que a vegetação de Cerrado possui essa característica (LIU et al., 2016; ZYLSTRA et al., 2016).

Em consequência da importância da microrregião de Barreiras e pelas queimadas anuais em seu território, o presente trabalho busca a detecção e quantificação de áreas atingidas por eventos de queima através de sensores óticos, ao longo da microrregião de Barreiras no período de 2015 a 2019.

\section{REVISÃO TEÓRICA}

\section{Área de estudo}

A microrregião de Barreiras, situada no estado da Bahia (Figura 1), possui grande destaque no cenário agrícola nacional. A região faz parte da fronteira agrícola denominada MATOPIBA, criada com as iniciais dos estados do Maranhão, Tocantins, Piauí e Bahia. Sendo uma microrregião com uma agricultura moderna e especializada, principalmente em áreas de cultivo de soja, milho e algodão herbáceo, destacando-se os municípios de Barreiras, Luís Eduardo Magalhães e São Desiderio.

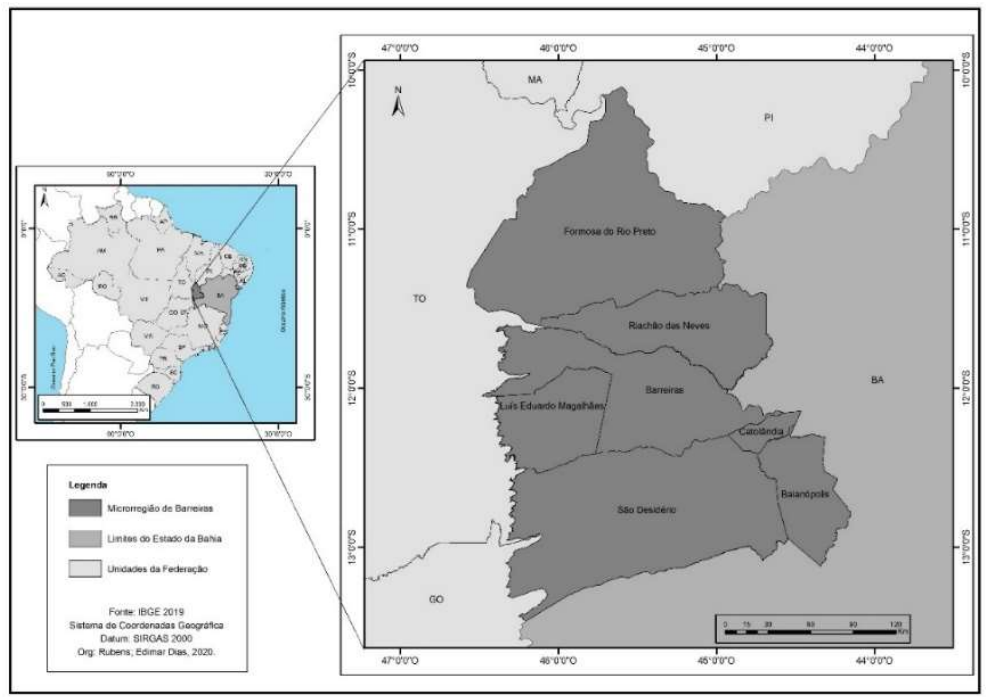

Figura 1: Microrregião de Barreiras - Bahia.

A microrregião de Barreiras possui aproximadamente $53.000 \mathrm{~km}^{2}$ (AIBA, 2015) e é constituída por sete municípios: Barreiras, Luís Eduardo Magalhães, São Desidério, Formosa do Rio Preto, Riachão das Neves, Baianópolis e Catolândia (Figura 1).

A temperatura média anual varia de $22^{\circ}$ a 27으 (MALHEIROS, 2016), sendo o clima classificado como do tipo Aw, conforme a classificação climática de Köppen-Geiger (ÁLVARES et al., 2013). O bioma da 
microrregião é o Cerrado, sendo caracterizado por possuir épocas do ano bem definidas, com chuvas de primavera/verão e período seco no outono/inverno, e o clima na maioria da extensão é tropical de caráter subúmido (BASTOS et al., 2010). Naturalmente, o solo apresenta-se com diversas formações, sendo encontrados solos menos intemperizados, como os Neossolos, e solos mais intemperizados, como os Latossolos; porém, como o material de origem é semelhante, possuem a caraterística de alta acidez e baixa disponibilidade de nutrientes (KLINK et al., 2005).

\section{METODOLOGIA}

Para a detecção e quantificação de áreas atingidas por eventos de queimada na microrregião de Barreiras foram utilizados dados de foco de calor adquiridos no site do Instituto Nacional de Pesquisas Espaciais (INPE), oriundos do satélite NOAA-19, para o período de 2015 a 2019. Segundo INPE (2011), uma matéria em combustão irradiar energia na faixa termal-média de 3,7 a 4.1 micrómetros do espectro ótico. Utilizam-se dessa forma as imagens que tenham esta faixa característica e nelas os píxeis (elementos de resolução) com maior temperatura em geral.

Para analisar a densidade dos focos de calor foi utilizado o método de densidade de Kernel, que possibilitou gerar mapas para estimativas de densidade da distribuição de focos de calor e assim identificar áreas que houve maior ou menor ocorrência de focos, através das classificações Baixa, Média, Alta e Muito Alta, descrita em intervalos ente $<0,03$ a $>0,09$, como pode visto na Tabela 1.

Tabela 1: Área com focos de calor na Microrregião de Barreiras - BA.

\begin{tabular}{|l|l|}
\hline Classes & Intervalos \\
\hline Baixa & $<0,03$ \\
\hline Média & $0,03-0,06$ \\
\hline Alta & $0,061-0,09$ \\
\hline Muito Alta & $>0,09$ \\
\hline
\end{tabular}

O mapa de Kernel é uma ferramenta que permite resultados satisfatórios no estudo de queimadas. O mapa é plotado, através do método de interpolação, onde a intensidade pontual do fenômeno em toda a região de estudo é avaliada. Assim, temos uma visão geral da intensidade do processo em todas as regiões do mapa (SOUZA et al., 2013).

Além da distribuição e densidade dos focos de calor, foi analisada a sua relação com a precipitação nos anos analisados. Para tanto foram utilizados dados de pluviometria disponibilizados nos portais da Agência Nacional de Águas (ANA) e Instituto Nacional de Meteorologia (INMET) na internet, conforme Tabela 2.

Tabela 2: Estações pluviométricas utilizadas.

\begin{tabular}{|l|l|l|l|l|l|}
\hline CÓDIGO & ESTAÇÃO & MUNICíPIO & UF & RESPONSÁVEL & OPERADORA \\
\hline 1344025 & Sítio Januário & Correntina & BA & ANA & CPRM \\
\hline 1244020 & Cera & São Desidério & BA & ANA & CPRM \\
\hline 1245016 & Cabeceira Grande & São Desidério & BA & ANA & CPRM \\
\hline 1145020 & Fazenda Triunfo & Formosa do Rio Preto & BA & ANA & CPRM \\
\hline 1045006 & Coaceral & Formosa do Rio Preto & BA & ANA & CPRM \\
\hline 1346007 & Fazenda Prainha (Faz. Antas) & São Desidério & BA & ANA & CPRM \\
\hline 1245007 & Sítio Grande & São Desidério & BA & ANA & CPRM \\
\hline
\end{tabular}




\begin{tabular}{|c|c|c|c|c|c|}
\hline 1245014 & Fazenda Johá & Barreiras & BA & ANA & CPRM \\
\hline 1245015 & Roda Velha & São Desidério & BA & ANA & CPRM \\
\hline 86652 & Barreiras_A402 & Barreiras & BA & INMET & INMET \\
\hline 1244019 & Fazenda Coqueiro & São Desidério & BA & ANA & CPRM \\
\hline 1245004 & Fazenda Redenção & Barreiras & BA & ANA & CPRM \\
\hline 1245005 & Derocal & São Desidério & BA & ANA & CPRM \\
\hline 1145001 & Formosa do Rio preto & Formosa do Rio Preto & BA & ANA & CPRM \\
\hline 1144014 & São Sebastião & Angical & BA & ANA & CPRM \\
\hline 1145019 & Cariparé & Riachão das Neves & BA & ANA & CPRM \\
\hline 1145004 & Fazenda Bom Jardim & Formosa do Rio Preto & BA & ANA & CPRM \\
\hline 1145013 & Ponte Serafim - Montante & Barreiras & BA & ANA & CPRM \\
\hline 1145014 & Nova Vida - Montante & Barreiras & BA & ANA & CPRM \\
\hline 1244021 & Brejo Novo & Barreiras & BA & ANA & CPRM \\
\hline 1345002 & Casa Real & São Desidério & BA & ANA & CPRM \\
\hline 1245017 & Limoeiro & Barreiras & BA & ANA & CPRM \\
\hline 1145024 & Rio Limpo & Barreiras & BA & ANA & CPRM \\
\hline 1146005 & Cacimbinha & Formosa do Rio Preto & BA & ANA & CPRM \\
\hline 1146006 & Fazenda Otake & Formosa do Rio Preto & BA & ANA & CPRM \\
\hline 1244023 & Lagoa Clara & Baianópolis & BA & ANA & CPRM \\
\hline 1346000 & São Domingos & São Domingos & GO & ANA & CPRM \\
\hline 1246000 & Ponte Alta do Bom Jesus & Ponte Alta do Bom Jesus & TO & ANA & CPRM \\
\hline
\end{tabular}

Buscou-se selecionar as estações pluviométricas que apresentaram dados consistentes nos anos analisados. Com os dados referentes a precipitação anual média na microrregião de Barreiras, foi utilizado o método do Inverso da Distância Ponderada (IDW) para gerar mapas de índices pluviométricos. O IDW atribui um peso maior paras as amostras mais próximas e um menor peso as amostras mais distantes (JIMENEZ et al., 2008).

\section{RESULTADOS E DISCUSSÃO}

Temperaturas elevadas e períodos secos, com baixa umidade, característicos do bioma Cerrado, favorecem a ocorrência de incêndios. A Tabela 3 apresenta a quantidade de focos de calor na microrregião de Barreiras - Bahia, no período de 2015 - 2019.

Tabela 3: Quantitativo de focos de calor na microrregião de Barreiras - BA.

\begin{tabular}{|c|c|c|c|c|c|}
\hline \multirow[b]{2}{*}{ Município } & \multicolumn{5}{|c|}{$N^{\circ}$ de focos } \\
\hline & 2015 & 2016 & 2017 & 2018 & 2019 \\
\hline Baianópolis & 67 & 24 & 78 & 55 & 32 \\
\hline Barreiras & 174 & 104 & 223 & 84 & 89 \\
\hline Catolândia & 4 & 0 & 0 & 2 & 5 \\
\hline Formosa do Rio Preto & 813 & 294 & 540 & 224 & 382 \\
\hline Luís Eduardo Magalhães & 15 & 18 & 137 & 74 & 37 \\
\hline Riachão das Neves & 366 & 41 & 157 & 156 & 168 \\
\hline São Desidério & 290 & 187 & 375 & 143 & 271 \\
\hline Total & 1729 & 668 & 1510 & 738 & 984 \\
\hline
\end{tabular}

Fonte: Satélite NOAA - 19, INPE (2020).

O ano de 2015 apresentou o maior número de queimadas na microrregião de Barreiras, seguido de uma redução no ano de 2016 de aproximadamente 1061 focos. Em 2017 em comparação a 2015 houve aproximadamente uma redução de 219 focos, já contrapondo com o ano de 2018 e 2019, a redução respectivamente foi de 991 e 745 focos de calor. Em 2019 em Catolândia os números de focos de incêndios aumentaram, em comparação temporal, divergente dos outros que relativamente tiveram diminuição em relação aos focos de incêndios observados no ano de 2015. A Figura 2 apresenta o percentual de focos de 
calor por município da microrregião de Barreiras.

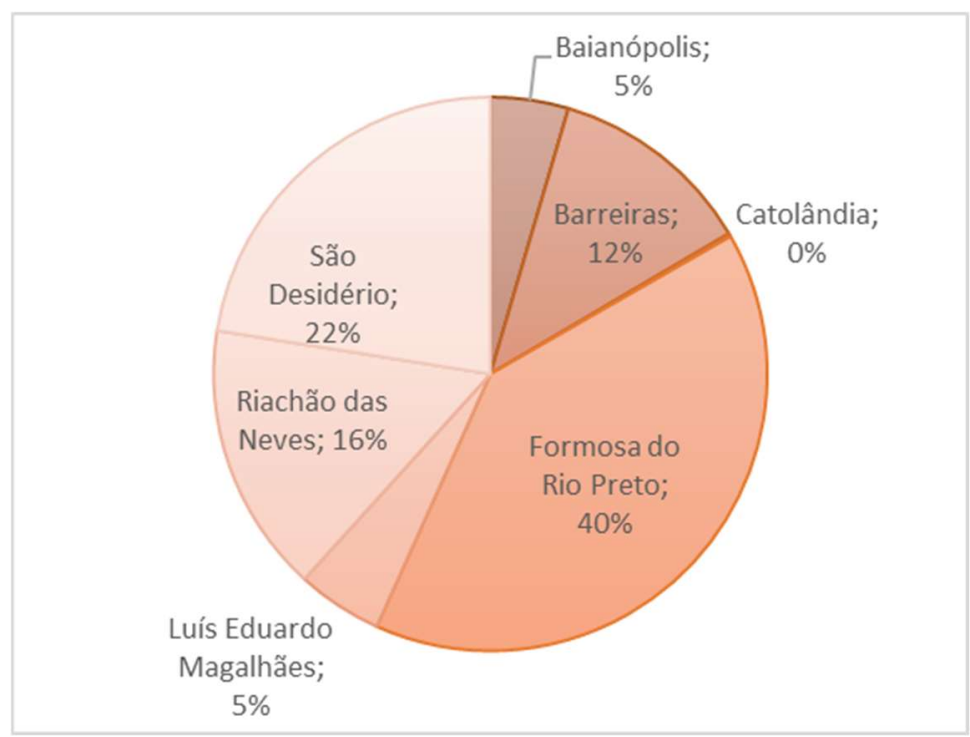

Figura 2: Percentual de focos de calor por município da microrregião Barreiras - BA entre os anos de 2015 a 2019.

No município de Baianópolis foram identificados nos últimos 5 anos 256 focos de calor, o que representa um percentual de 5\% na região. A média foi de proximamente 51 focos, sendo em 2016 o ano com menor quantidade de registros como pode ser observado, e em 2017 registra-se 78 focos de calor, o maior valor encontrado.

Em Barreiras registra-se no período analisado o total de 674 focos de calor, com um percentual de 12\% na região e uma média de aproximadamente 134 focos nos últimos 5 anos, e um maior número de incêndios no ano de 2017. O ano 2018 foi o que apresentou um menor número de ocorrência de incêndios no município de Barreiras (Tabela 3).

Em Formosa do Rio Preto, que possui $40 \%$ dos focos de incêndio identificados no período analisado, em 2015 foram observados 813 focos (ano com maiores focos registrados) e uma média de cerca de 450 focos nos últimos 5 anos. $\mathrm{O}$ ano com o menor número de ocorrência de incêndios em Formosa do Rio Preto foi o ano de 2018, com 224 registros.

No município de Luís Eduardo Magalhães, que apresenta apenas 5\% das ocorrências no período, a média foi de aproximadamente 56 focos de incêndios, com o ano de 2017 figurando como o ano de maior registro de ocorrências. Já o ano que apresentou uma menor ocorrência foi o ano de 2015, com apenas 15 focos de incêndios. Em Riachão das Neves, que apresenta 16\% das ocorrências, as médias encontradas são maiores do que os observados em Baianópolis, Barreiras, Catolândia, e Luís Eduardo Magalhães, com um total de 888 focos nos últimos 5 anos e uma média de 177 focos de incêndio. Em 2015 ocorreu o maior número de incêndios (366), e em 2016 o menor valor comparado com os outros anos no município, 41 focos de incêndios.

Em São Desiderio, que apresenta 22\% das ocorrências, foram detectados 1.266 focos de incêndios nos últimos 5 anos, com uma média de aproximadamente 253 focos. Os maiores números de focos foram identificados no ano de 2017 (375), e menor número observado em 2018, com 143 focos de calor, sendo o segundo município a apresentar maior número de registro de focos de incêndio, logo atrás de Formosa do 
Rio Preto. A Figura 3 apresenta a distribuição espacial dos focos de calor na microrregião de Barreiras/BA para o período de 2015 - 2019.

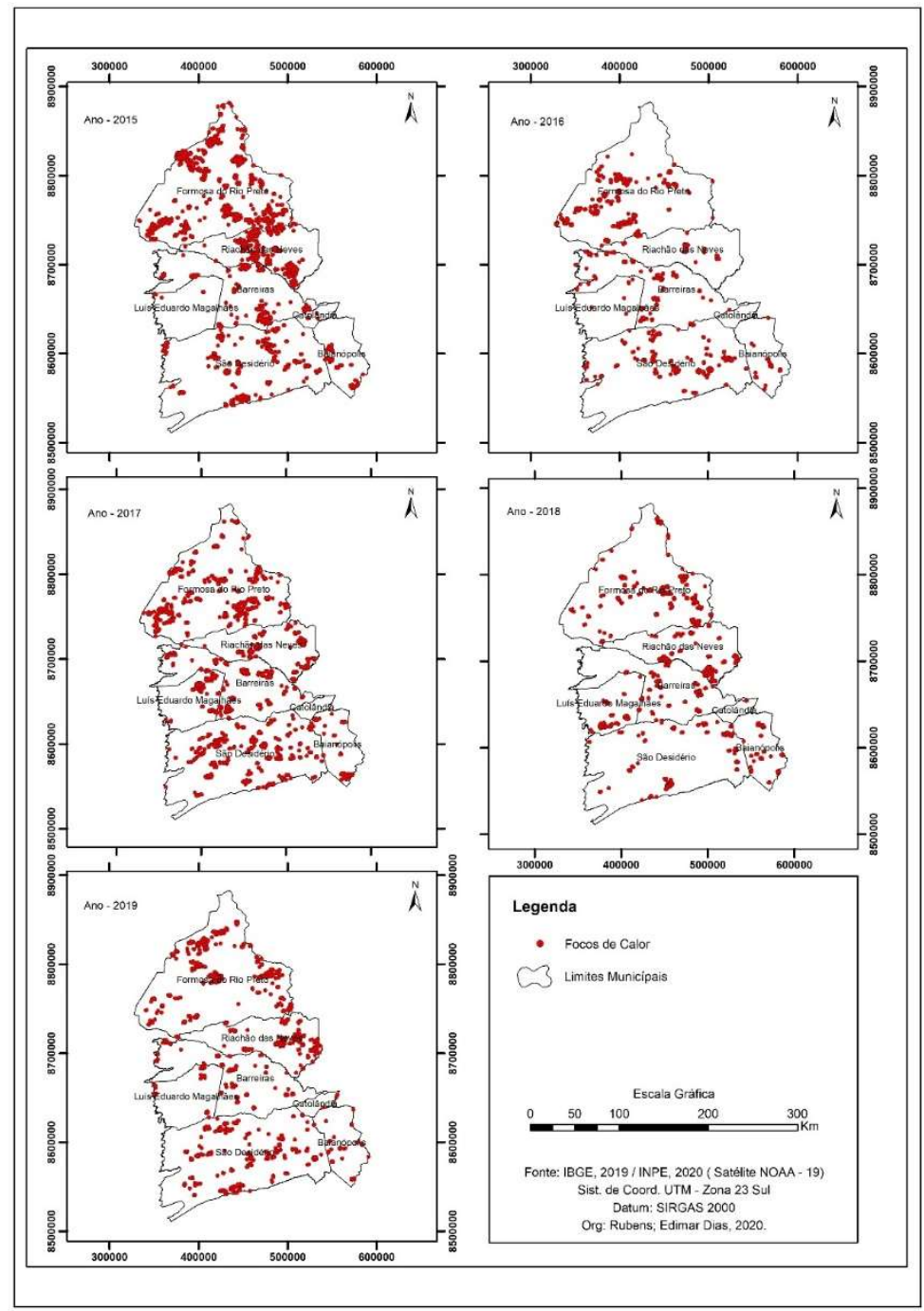

Figura 3: Focos de calor na microrregião de Barreiras - BA entre os anos de 2015 a 2019.

Observa-se que a distribuição dos focos de calor na microrregião de Barreiras é intensa, apresentando uma ampla distribuição espacial em toda a região (Figura 3), o que acaba também dificultando as ações de combate e prevenção de incêndios

Observa-se ainda na Figura 3 que os anos de 2015, 2017 e 2019 foram os que tiveram o maior número de focos de incêndio, com ampla distribuição espacial e os demais anos a ocorrência de focos foi menor.

Abreu et al. (2016), em estudo na região leste do estado de Mato Grosso, com vegetação tipicamente de Cerrado e com o clima da região do tipo Aw, clima quente e úmido, com duas estações definidas (verão chuvoso e inverno seco), com duração de 5 anos (2005-2010), verificaram ao realizar a sobreposição entre os dados de focos de calor com os de desmatamento que não há relação entre os dois temas dentro da área de estudo verificada, já que essas áreas possuem baixa porcentagem de áreas desmatadas, o que contrasta com Aragão et al. (2009), que afirma que existe uma forte relação entre focos de calor e atividades de desmatamento. A Figura 4 apresenta a densidade de focos de calor na Microrregião de Barreiras. 


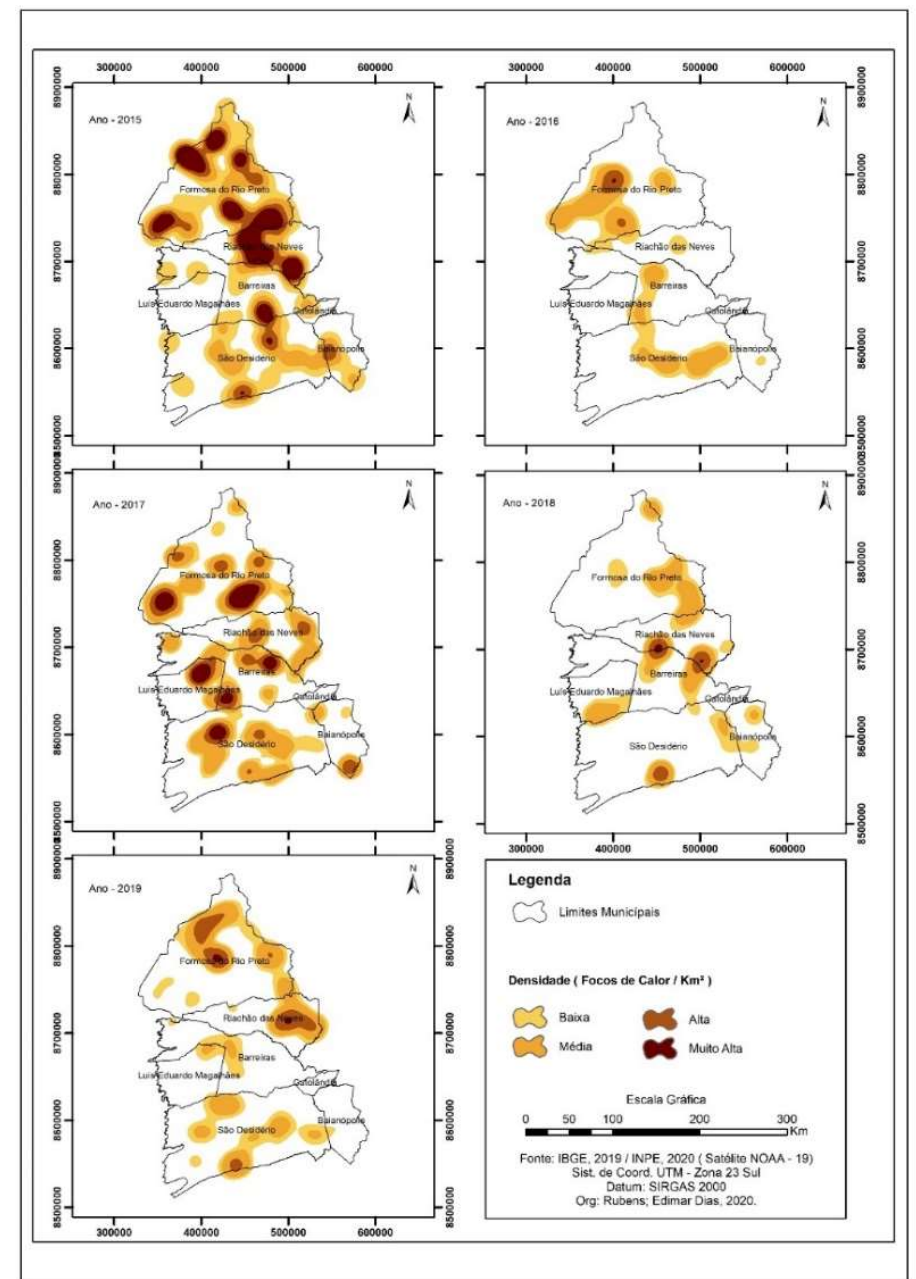

Figura 4: Densidade de focos de calor da microrregião de Barreiras - BA entre os anos de 2015 a 2019.

Os municípios de Formosa do Rio Preto, Riachão das Neves e São Desidério apresentam a maior densidade de focos de calor, e as maiores áreas das classes Muito Alta e Média. Diversos fatores podem influenciar esses padrões, a exemplo do uso do solo, renovação dos solos para cultivo e pastagem, níveis de umidade e temperatura atmosférica entre outros (LOPES et al., 2017; OLIVEIRA et al., 2017).

As áreas com muitos focos de calor, apresentam as queimadas como um dos agentes de degradação, servindo de alerta para monitoramento e contenção de práticas não controladas e atuação eficiente dos órgãos ambientais responsáveis (FLORES et al., 2015; NARDINI et al., 2015; DIOGENES et al., 2018). França (2018), afirma que as taxas de densidade Muito Alta apresentam elevadas taxas de fragilidade ambiental potencial, coincidindo com as mesmas áreas a ocorrência de elevados focos de calor anualmente. O que segundo o autor são ocasionados por múltiplos fatores ambientais, e é fundamental estudos nesses locais para evitar a degradação de áreas associados à incêndios.

Tabela 4: Densidade por área na Microrregião de Barreiras - BA entre 2015 a 2019.

\begin{tabular}{|l|l|l|l|l|l|}
\hline & $\mathbf{2 0 1 5}$ & $\mathbf{2 0 1 6}$ & $\mathbf{2 0 1 7}$ & $\mathbf{2 0 1 8}$ & $\mathbf{2 0 1 9}$ \\
\hline Classes & Área $\mathbf{K m}^{\mathbf{2}}$ & \multicolumn{5}{l|}{} \\
\hline Baixa & 15544,89 & 6272,96 & 8731,20 & 6092,70 & 8260,64 \\
\hline Média & 8848,92 & 6043,27 & 12291,54 & 5347,65 & 6939,29 \\
\hline Alta & 4464,13 & 589,91 & 3444,02 & 987,37 & 2022,80 \\
\hline Muito Alta & 4989,88 & 19,95 & 2084,44 & 90,74 & 129,20 \\
\hline Total & 33847,82 & 12926,09 & 26551,20 & 12518,46 & 17351,93 \\
\hline
\end{tabular}


Na Tabela 4 é possível perceber que durante os últimos cinco anos, praticamente todos os focos foram classificados na classe Baixa e Média na microrregião de Barreiras, respectivamente entre 2015 a 2019 , o equivalente a $72 \%, 95 \%, 79 \%, 91 \%, 88 \%$ somente essas duas classes, sendo a classe Baixa correspondente anualmente nessa ordem por $46 \%, 49 \%, 33 \%, 49 \%$, e $48 \%$. A classe Alta corresponde por $13 \%, 5 \%, 13 \% ; 8 \%$ e $12 \%$ e Muito Alto o equivalente a $15 \%, 0 \%, 8 \%, 1 \%$, e $1 \%$ respectivamente nos cincos anos avaliados.

Sendo possível perceber na tabela acima de densidade da microrregião que apenas em 2015 houve um percentual alto na classe Muito Alta equivalente a 15\%, e a média em geral entre 2015 a 2019 da densidade é de $45 \%$ na classe Baixa, $40 \%$ na classe Média, 10\% em Alta e Muito Alta com 5\%.

A ocorrência de incêndios, em grande quantidade e de forma especializada, conforme ocorre na microrregião de Barreiras, podem prejudicar o meio ambiente, atingindo a vegetação nativa, matando animais silvestres, espécies endêmicas e pode chegar em áreas urbanas (COCHRANE, 2009). Dessa forma, fica evidente a necessidade de se ter a atenção voltada à fiscalização, principalmente nessas áreas de maior potencialidade à ocorrência de incêndios florestais.

Acredita-se que os focos de incêndios podem ser maiores do que os detectados nesse estudo, pois estudos realizados na região Norte do Brasil, evidenciam omissões dos satélites na captação de focos de calor (PANTOJA et al., 2005; PANTOJA et al., 2007). Sob a mesma ótica, Tomzhinski et al. (2011), ao compararem os registros dos focos de calor, puderam concluir que os satélites deixaram de detectar 96\% das ocorrências de incêndios de pequeno porte analisadas, menores que 10 ha, levando em conta apenas os de médio, entre 10 e 52 ha, e de grande porte, maiores que 700 ha.

O bioma Cerrado é caracterizado por possuir épocas do ano bem definidas, que segundo Bastos et al. (2010) possui épocas com chuvas de primavera/verão e período seco no outono/inverno. Os dados pluviométricos, permitem a análise da tendência de uma região sofrer queimadas naturais principalmente por fatores como a baixa umidade do ar e incidências de raios. A Tabela 5 apresenta as médias anuais dos postos pluviométricos da microrregião de Barreiras.

Tabela 5: Média anual de precipitação de postos pluviométricos da microrregião de Barreiras - BA

\begin{tabular}{|c|c|c|c|c|c|c|c|c|}
\hline \multirow{2}{*}{\multicolumn{2}{|c|}{ Estação }} & \multirow{3}{*}{$\begin{array}{l}\text { Latitude } \\
-13,083333\end{array}$} & \multirow{3}{*}{$\begin{array}{l}\text { Longitude } \\
-44,716944\end{array}$} & \multicolumn{5}{|c|}{ Precipitação (mm) } \\
\hline & & & & \multirow{2}{*}{$\begin{array}{l}2015 \\
528,0 \\
\end{array}$} & \multirow{2}{*}{\begin{tabular}{|l|}
2016 \\
937,8 \\
\end{tabular}} & \multirow{2}{*}{$\begin{array}{l}2017 \\
1104,3 \\
\end{array}$} & \multirow{2}{*}{$\begin{array}{l}2018 \\
1150,2\end{array}$} & \multirow{2}{*}{$\begin{array}{l}2019 \\
1061,5 \\
\end{array}$} \\
\hline 1 & Sítio Januário & & & & & & & \\
\hline 2 & Cera & $-12,993611$ & $-44,806111$ & 522,9 & 706,4 & 844,2 & 880,3 & 915,6 \\
\hline 3 & Cabeceira Grande & $-12,663611$ & $-45,019444$ & 638,0 & 729,1 & 990,9 & 1321,8 & 1051,7 \\
\hline 4 & Fazenda Triunfo & $-11,460278$ & $-45,615278$ & 818,6 & 845,1 & 993,2 & 1346,3 & 713,8 \\
\hline 5 & Coaceral & $-10,562222$ & $-45,695000$ & 960,0 & 1110,4 & 993,8 & 1401,7 & 801,7 \\
\hline 6 & Fazenda Prainha (Faz. Antas) & $-13,312500$ & $-46,063056$ & 658,3 & 801,6 & 823,2 & 1299,0 & 766,3 \\
\hline 7 & Sítio Grande & $-12,430556$ & $-45,085833$ & 748,5 & 1064,8 & 782,3 & 1033,8 & 676,4 \\
\hline 8 & Fazenda Johá & $-12,125556$ & $-45,810833$ & 721,8 & 890,8 & 761,5 & 1097,5 & 540,4 \\
\hline 9 & Roda Velha & $-12,765278$ & $-45,943889$ & 605,2 & 963,7 & 1110,8 & 1081,4 & 661,5 \\
\hline 10 & Barreiras & $-11,154444$ & $-45,009167$ & 800,9 & 1037,1 & 659,5 & 866,5 & 739,3 \\
\hline 11 & Fazenda Coqueiro & $-12,389167$ & $-44,932222$ & 928,8 & 1107,2 & 944,4 & 1341,8 & 1097,1 \\
\hline 12 & Fazenda Redenção & $-45,027049$ & $-45,104167$ & 699,2 & 1056,5 & 769,2 & 1115,6 & 611,5 \\
\hline 13 & Derocal & $-12,411389$ & $-45,120278$ & 512,7 & 1120,0 & 747,0 & 1337,4 & 880,4 \\
\hline 14 & Formosa do Rio Preto & $-11,047778$ & $-45,201944$ & 651,8 & 1019,9 & 811,7 & 1109,1 & 777,1 \\
\hline 15 & São Sebastião & $-11,979444$ & $-44,877222$ & 567,4 & 989,8 & 887,6 & 775,8 & 489,5 \\
\hline 16 & Cariparé & $-11,511944$ & $-45,041944$ & 677,4 & 895,4 & 991,4 & 1105,9 & 808,0 \\
\hline 17 & Fazenda Bom Jardim & $-10,992500$ & $-45,526667$ & 862,9 & 1101,2 & 1028,7 & 1164,7 & 794,5 \\
\hline 18 & Ponte Serafim - Montante & $-11,896111$ & $-45,611944$ & 1097,8 & 1097,8 & 981,6 & 1336,4 & 967,1 \\
\hline
\end{tabular}




\begin{tabular}{|l|l|l|l|l|l|l|l|l|}
\hline 19 & Nova Vida - Montante & $-11,852500$ & $-45,122222$ & 592,7 & 963,7 & 904,5 & 1012,3 & 810,6 \\
\hline 20 & Brejo Novo & $-12,232222$ & $-44,934167$ & 1410,0 & 554,6 & 919,3 & 1132,3 & 713,2 \\
\hline 21 & Casa Real & $-13,015278$ & $-45,630833$ & 293,3 & 763,1 & 605,2 & 982,6 & 496,3 \\
\hline 22 & Limoeiro & $-12,290833$ & $-45,544722$ & 625,7 & 1050,7 & 1012,6 & 1024,9 & 750,4 \\
\hline 23 & Rio Limpo & $-11,713889$ & $-45,974167$ & 716,8 & 943,6 & 1116,2 & 1362,6 & 1101,4 \\
\hline 24 & Cacimbinha & $-11,151944$ & $-46,060833$ & 1009,2 & 868,7 & 1154,4 & 1564,9 & 848,2 \\
\hline 25 & Fazenda Otake & $-11,540833$ & $-46,236944$ & 952,2 & 743,1 & 1006,2 & 1475,9 & 928,4 \\
\hline 26 & Lagoa Clara & $-12,660556$ & $-44,389167$ & 584,6 & 638,9 & 1085,2 & 1044,3 & 790,1 \\
\hline 27 & São Domingos & $-13,397500$ & $-46,315833$ & 987,6 & 936,6 & 1218,4 & 1314,6 & 887,0 \\
\hline 28 & Ponte Alta do Bom Jesus & $-12,090833$ & $-46,479444$ & 1213,5 & 1377,8 & 1207,7 & 1998,1 & 1145,3 \\
\hline \multicolumn{2}{|l|}{ Médias } & 763,8 & 939,8 & 944,8 & 1202,8 & 815,2 \\
\hline
\end{tabular}

De modo geral o bioma Cerrado apresenta o período com chuvas regulares e espaçadas durante o ano (MALHEIROS, 2016) o que agrava ainda mais a dinâmica das queimadas na região. Com uma taxa de precipitação baixa, o clima passar a propiciar a ocorrência das queimadas, uma vez que altera a umidade do ar tornando a vegetação suscetível a eventos naturais ou antrópicos.

Na Tabela 5 é possível verificar os dados pluviométricos de todas as estações nas proximidades dos munícipios que fazem parte da microrregião de Barreiras, o que possibilita aferir uma relação indireta entre pluviometria e baixo número de incêndios na microrregião. Analisando os dados obtidos no ano 2015 em comparação a 2019, a diferença de volume pluviométrico é de $6 \%$ menor em 2019, enquanto os números de focos de calor são de cerca de 57\% dos focos em 2015. O volume da pluviometria em 2016 e 2017 são 99\% equivalentes, enquanto que o número de focos de calor em 2016 são 56\% menor do que o detectado em 2017.

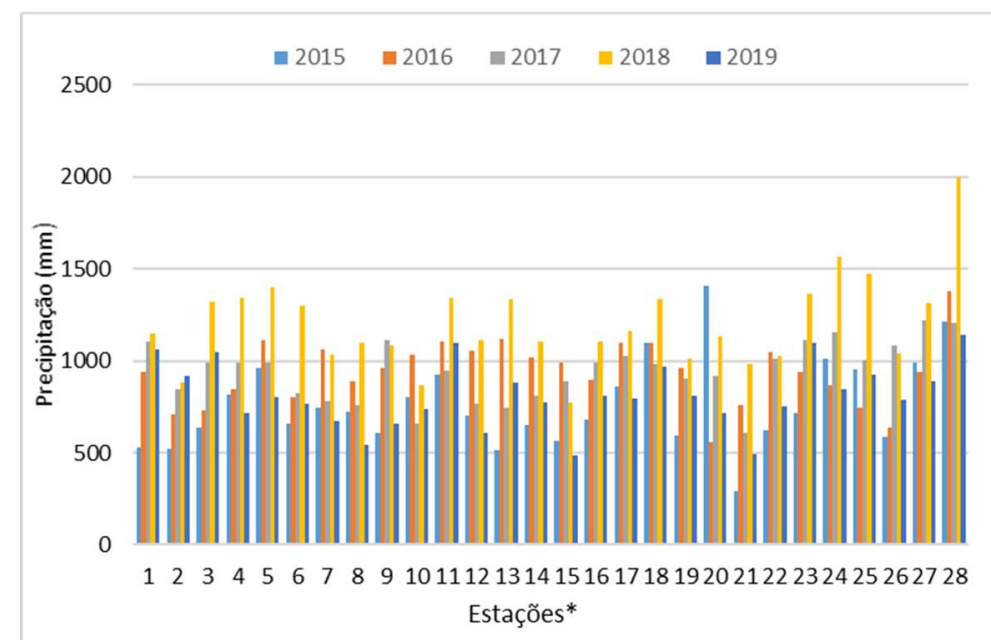

Figura 5: Precipitação de postos pluviométricos na proximidade da microrregião de Barreiras — Ba. *As estações foram nomeadas de 1 a 28 conforme a respectiva ordem apresentada na Tabela 5.

O ano mais chuvoso nesses últimos 5 anos foi o ano de 2018 como pode-se observar na Figura 5 . Nesse ano a maioria dos postos pluviométricos registraram maiores índices de precipitação, com exceção das estações 2 (Cera), 7 (Sítio Grande), 9 (Roda Velha), 10 (Barreiras), 15 (São Sebastião), 20 (Brejo Novo), 22 (Limoeiro), e 26 (Lagoa Clara). Em comparação com os anos de 2015, 2016, 2017 e 2019 o volume precipitado no ano de 2018 foi superior 36, 22, 21 e 32\%, respectivamente.

Lopes et al. (2019) com estudos de 1961 a 2016 para microrregião de Barreiras, observou a ocorrência da precipitação para a microrregião baiana, onde a cada dois anos pode ocasionar uma 
precipitação máxima anual igual ou superior a 1050 mm, constatou ainda variações no período, havendo anos com secas prolongadas e outros chuvosos; sendo aferido o período de menor disponibilidade de água no solo entre agosto a setembro, devido a evapotranspiração. Os autores observaram que acontece de outubro a março o período de chuvas, porém, há uma maior reposição no balanço hídrico de novembro a março. A Figura 6 apresenta o comparativo da precipitação na microrregião de Barreiras com a ocorrência de focos de calor.

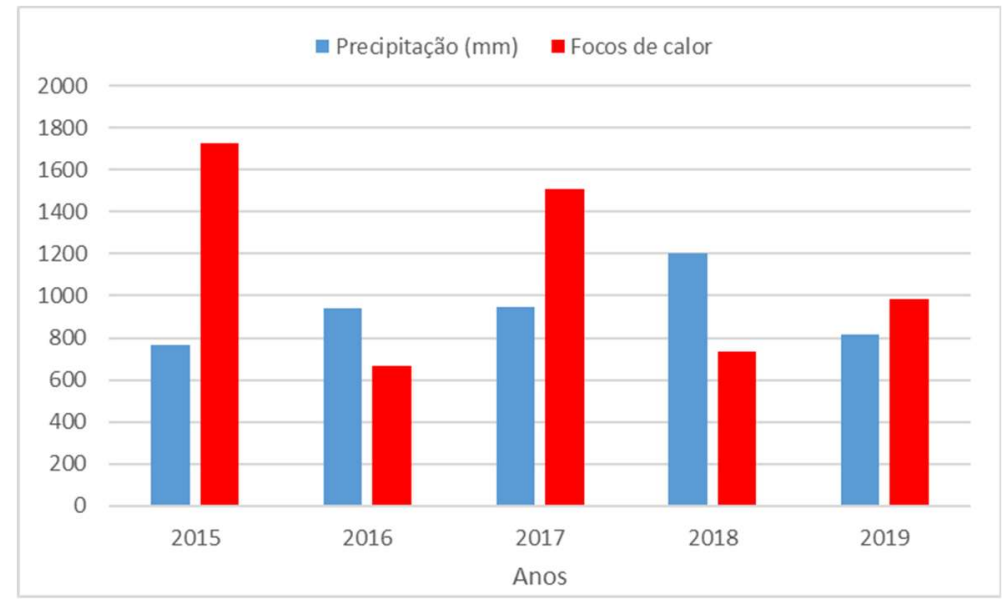

Figura 6: Comparativo da precipitação e focos de calor na microrregião de Barreiras.

Segundo White et al. (2011) existe uma influência de redução dos focos de incêndio, a depender diretamente da água precipitada. Com base na análise da Figura 6 é possível indicar que quantidade de precipitação registrada na região, mesmo que de forma assimétrica, pode ter influenciado na ocorrência de focos de incêndio na região. Os anos de 2015 e 2019 apresentaram os menores índices pluviométricos e a maior quantidade de focos de incêndio, chegando o ano de 2015 a ter maior número de ocorrências. Os anos de 2016 e 2018 apresentaram os maiores índices pluviométricos e consequentemente os menores números de focos de calor, embora 2016 com uma precipitação um pouco maior, tenha apresentado um número menor de focos de calor quando comparado com 2018.

O ano que se apresentou mais destoante foi o ano de 2017, que apresentou um índice pluviométrico semelhante a 2016 e próximo aos anos de 2015 e 2019, mas por outro lado, apresentou o segundo maior número de focos de calor. Isso pode ser decorrente da distribuição espacial e temporal das chuvas, disponibilidade de vegetação disponível em condições favoráveis a combustão natural no bioma e queimadas acidentais ou criminosas. A Figura 6 apresenta a distribuição espacial da precipitação na microrregião de Barreiras.

Nos mapas pluviométricos apresentados na Figura 6 é possível observar uma maior incidências de chuvas nas proximidades do município de Formosa do Rio Preto no Oeste da Bahia, onde encontra-se a área para desenvolvimento do projeto Corredor Ecológico da Região do Jalapão e a APA do Rio de Janeiro, onde segundo Almeida (2010), a bacia hidrográfica no ano de 1984 estava praticamente ocupada pela vegetação natural (88,2\%), enquanto que em 2009 apenas 54,42\% correspondia ao Cerrado, expandindo-se as áreas para culturas agrícolas de soja e algodão, principalmente. 


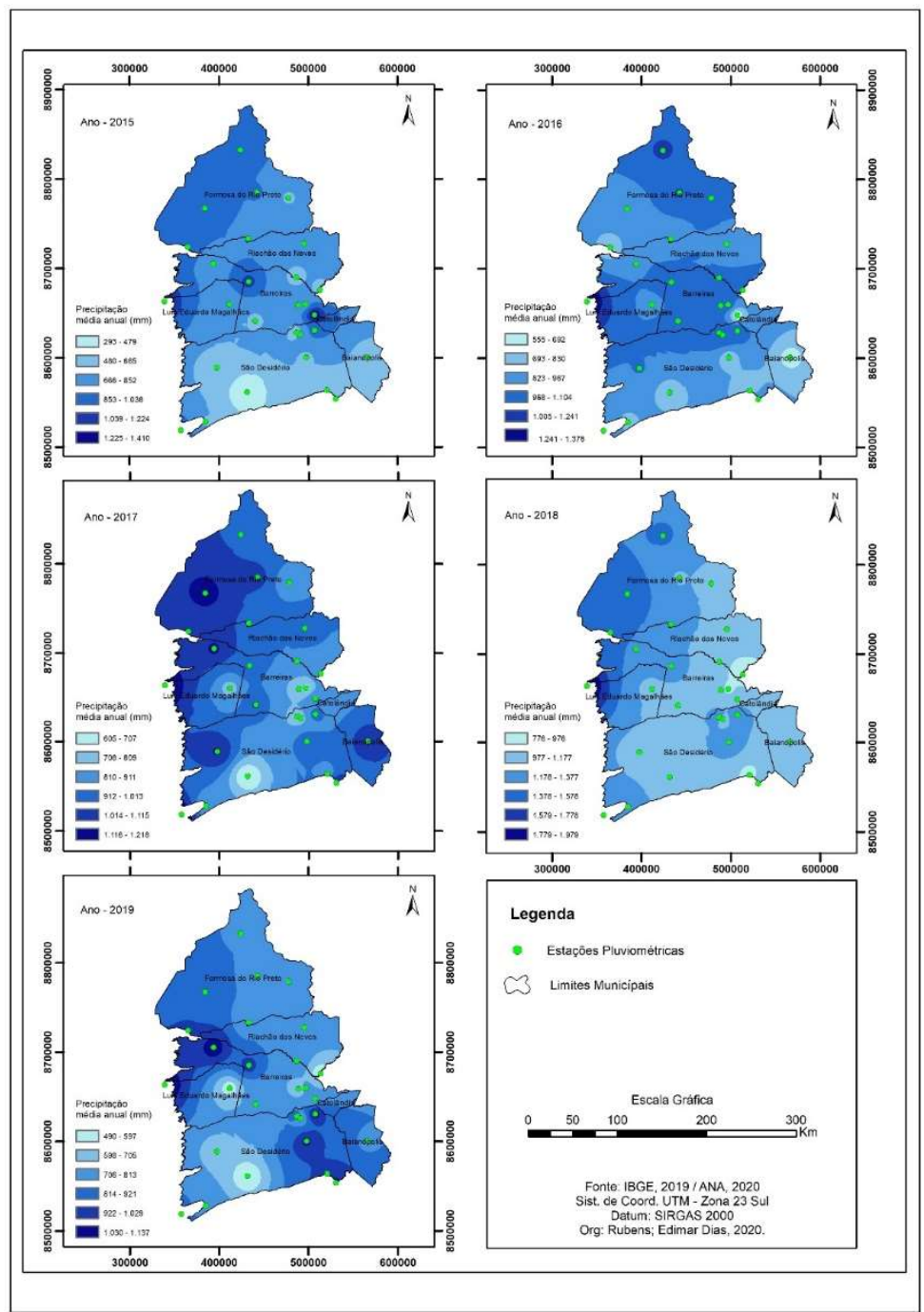

Figura 6: Distribuição pluviométrica na microrregião de Barreiras - Ba de 2015 a 2019.

Comparando a Figura 6 com as Figuras 3 e 4 observa-se que a distribuição da precipitação média anual não apresenta clara relação com a ocorrência e densidade de focos de calor. Isso pode ser decorrente da distribuição temporal da precipitação ao longo do ano, já que dependendo da época que ocorra as precipitações, elas não tenham relação ou capacidade de atenuar focos de calor que podem ser ocasionados inclusive por práticas intencionais, acidentais ou criminosas.

Portanto, estudos desta natureza, considerando as diversidades regionais intrínsecas de cada localidade e associando técnicas remotas de analise são capazes de criar bancos de dados eficientes para gestores, de modo a permitir o desenvolvimento de ações de planejamento integrado que minimizem os efeitos das queimadas que atingem grandes áreas e que tendem a alterar a dinâmica socioambiental.

\section{CONCLUSÕES}

Na microrregião de Barreiras observou-se uma maior ocorrência dos focos próximos as cidades de Barreiras, Formosa do Rio Preto, Riachão das Neves, e São Desidério e, com uma alternância na ocorrência de focos de calor nos 5 anos analisados. Os anos de 2015, 2017 e 2019 apresentaram um maior número de ocorrência, enquanto que os anos de 2016 e 2018 apresentaram números menores.

A ocorrência de focos de calor na microrregião de Barreiras ocorre de forma bem distribuída 
espacialmente o que dificulta as ações de prevenção e fiscalização.

Quando comparadas as ocorrências de focos de calor com a média anual precipitada, em cada ano, é possível indicar que quantidade de precipitação registrada na região, mesmo que de forma assimétrica, pode ter influenciado na ocorrência de focos de incêndio na região. Embora que quando comparadas a distribuição espacial dos focos de calor com a distribuição espacial da precipitação, não se observa clara relação entre ambos, já que a distribuição temporal da precipitação pode influenciar nesse processo, além da ocorrência queimadas por práticas intencionais, acidentais ou criminosas.

\section{REFERÊNCIAS}

ABREU, F. A.; SOUZA, J. S. A.. Dinâmica Espaço-temporal de Focos de Calor em Duas Terras Indígenas do Estado de Mato Grosso: uma Abordagem Geoespacial sobre a Dinâmica do Uso do Fogo por Xavantes e Bororos. Floresta e Ambiente, v.23, n.1, p.1-10, 2016. Dol: http://doi.org/10.1590/2179$\underline{8087.041813}$

AIBA. Associação de Agricultores e Irrigantes da Bahia. Anuário Agropecuário do Oeste da Bahia, safra 2014/2015. AIBA, 2015.

ALENCAR, A.; SHIMBO, J. Z.; LENTI, F.; MARQUES, C. B.; ZIMBRES, B.; ROSA, M.; ARRUDA, V.; CASTRO, I.; FERNANDES, J. P.; RIBEIRO, M.; VARELA, V.; ALENCAR, I. PIONTEKOWSKI, V.; RIBEIRO, V.; BUSTAMANTE, M. M. C.; SANO, E. E.; BARROSO, M.. Mapping Three Decades of Changes in the Brazilian Savanna Native Vegetation Using Landsat Data Processed in the Google Earth Engine Platform. Remote Sens, Brasília, v.12, n.924, 2020. DOI: http://doi.org/10.3390/rs12060924

ALMEIDA, R. S.. Mudanças no uso e cobertura do solo na Bacia do Rio de Ondas no período de 1984 a 2009.

Monografia (Bacharelado) - Universidade Federal da Bahia, Barreiras, 2010.

ÁLVARES, C. A.; STAPE, J. L.; SENTELHAS, P. C.; GONÇALVES, J. L. M.; SPAROVEK, G.. Köppen's climate classification map for Brazil. Meteorologische Zeitschrift. Meteorologische Zeitschrift, Brasília, v.22, n.6, p.711-728, 2013. DOI: http://doi.org/10.1127/0941-2948/2013/0507

ANA. Agência Nacional de Águas. Sistema Nacional de Informação de Informação sobre Recursos Hídricos - SNIRH. ANA, 2020.

ANDREAE, M. O.; MERLET, P.. Emission of trace gases and aerosols from biomass burning. Global Biogeochemist Cycles, Mainz, v.4, n.15, p.955-966, 2001. DOI: http://doi.org/10.1029/2000GB001382

ARAGÃO, L.; SHIMABUKURO, Y.; LIMA, A.; ANDERSON, L.; BARBIER, N.; SAATCHI S.. Utilização de produtos derivados de sensores orbitais para o estudo de queimadas na Amazônia. In: SIMPÓSIO BRASILEIRO DE SENSORIAMENTO REMOTO, 14. Anais. São José dos Campos: INPE, 2009.

BASTOS, L. A.; FERREIRA, I. M.. Composições fitofisionômicas do bioma Cerrado: estudo sobre o subsistema de Vereda. Espaço em Revista, Catalão, v.12, n.1, 2010.
CANSLER, C. A.; MCKENZIE, D.. Climate, fire size and biophysical setting control fire severity and spatial pattern in the northern Cascade Range, USA. Ecological Applications, v.24, n.5, p.1037-1056, 2014

CLEMENTE, S. S.; OLIVEIRA JÚNIOR, J. F.; LOUZADA, M. A. P.. Focos de calor na Mata Atlântica do Estado do Rio de Janeiro. Revista Brasileira de Meteorologia, v.32, p.669-677, 2017. DOI: https://doi.org/10.1590/0102-7786324014

COCHRANE, M. A.. Tropical Fire Ecology: Climate change, Land use and Ecosystem Dynamics. Chichester: Praxis Plublishing Ltd., 2009.

COLLINS, L.; BRADSTOCK, R. A.; PENMAN, T. D.. Can precipitation influence landscape controls on wildfire severity? A case study within temperate eucalypt forests of southeastern Australia. Int. J. Wildland Fire, v.23, p.9-20, 2014. DOI: http://doi.org/10.1071/WF12184

COPPOlETTA, M.; MERRIUAM, K. E.; COllins, B. M.. Postfire vegetation and fuel development influences fire severity patterns in reburns. Ecol. Appl., v.26, p.686-699, 2016. DOI: http://doi.org/10.1890/15-0225

DALDEGAN, G.; ROBERTS, D.; FIGUEIREDO R. F.. Spectral mixture analysis in Google Earth Engine to model and delineate fire scars over a large extent and a long time-series in a rainforest-savanna transition zone. Remote Sensing of Environment, v.26, n.3, p.686-699. DOI: http://doi.org/10.1016/j.rse.2019.111340

DINTWE, K.; OKIN, G. S.; XUE, Y.. Fire-induced albedo change and surface radiative forcing in sub-Saharan Africa savanna ecosystems: Implications for the energy balance. Journal of Geophysical Research: Atmospheres, v.122, n.12, p.61866201, 2017. DOI: http://doi.org/10.1002/2016JD026318

DIÓGENES, F. E. G.; GUIMARÃES, P. P.; BOTREL, R. T.. Ocorrência de incêndios florestais em Caicó e Natal/RN. Agropecuária Científica no Semiárido, Patos, v.14, n.1, p.8084, 2018.

FLANNIGAN, M. D.; KRAWCHUK, M. A.; GROOT, W. J.; WOTTON, B. M.; GOWMAN, L. M.. Implications of changing climate for global wildland fire. International Journal of Wildland Fire, v.18, n.5 p.483-507, 2009. DOI: http://doi.org/10.1071/WF08187

FLORES, R. K.; MISOCZKY, M. C.. Dos antagonismos na apropriação capitalista da água à sua concepção como bem 
comum. Organizações e Sociedade, Salvador, v.22, n.73 p.237-250, 2015. DOI: http://doi.org/10.1590/1984-9230733

FORKEL, M.; DORIGO, W.; LASSLOP, G.; TEUBNER, I.; CHUVIECO, E.; THONICKE, K.. A data-driven approach to identify controls on global fire activity from satellite and climate observations (SOFIA V1). Geoscientific Model Development, v.10, n.12, p.4443-4476, 2017. DOI: http://doi.org/10.5194/gmd-10-4443-2017

FRANÇA, L. C. J.. Fragilidade ambiental potencial da bacia hidrográfica do rio Jequitinhonha, Minas Gerais, Brasil. Dissertação (Mestrado em Ciência Florestal) - Universidade Federal dos Vales do Jequitinhonha e Mucurí, Diamantina, 2018.

GONÇALVES, H.; MENEGUZZO, I. S.; MORO, R. S.. Políticas públicas para a conservação do Bioma Cerrado no Estado do Paraná, Brasil. Terra Plural, v.13, n.1, p.138-152, 2019. DOI: http://doi.org/10.5212/TerraPlural.v.13i1.0009

GONINO, G. M. R.; FIGUEIREDO, B. R. S.; MANETTA, G. I.; ALVES, G. H. Z.; BENEDITO, E.. Fire increases the productivity of sugarcane, but it also generates ashes that negatively affect native fish species in aquatic systems. Science of the Total Environment, v.664, n.10, p.215-221, 2019. DOI: http://doi.org/10.1016/j.scitotenv.2019.02.022

HRADSKY, B.. Conserving Australia's threatened native mammals in predator-invaded, fire-prone landscapes. Wildlife Research, v.47, n.1, 2019. DOI: http://doi.org/10.1071/WR19027

INPE. Instituto Nacional de Pesquisas Espaciais. Monitoramento de Queimadas. INPE, 2020.

INPE. Instituto Nacional de Pesquisas Espaciais. Portal do Monitoramento de Queimadas e Incêndios. INPE, 2011.

JIMENEZ, K. Q.; DOMECQ, F. M.. Estimação de chuva usando métodos de interpolação. Porto Alegre: Universidade Federal do Rio Grande do Sul, 2008.

KEELEY, J. E.; SYPHARD, A. D.. Climate change and future fire regimes: examples from California. Geosciences, v.6, n.3, p.37, 2016. DOI:

http://doi.org/10.3390/geosciences6030037

KLINK, C. A.; MACHADO, R. B.. A conservação do Cerrado Brasileiro. Revista Megadiversidade, Belo Horizonte, v.1, n.1 p.148-155, 2005.

KUKAVSKAYA, E. A.; BURYAK, L. V.; KALENSKAYA, O. P.; ZARUBIN, D. S.. Transformation of the Ground Cover after Surface Fires and Estimation of Pyrogenic Carbon Emissions in the Dark-Coniferous Forests of Central Siberia.

Contemporary Problems of Ecology, v.10, p.62-70, 2017. DOI: http://doi.org/10.1134/S1995425517010073

LEAHY, L.; LEGGE, S. M.; TUFT, K.; MCGREGOR, H. W.; BARMUTA, L. A.; JONES, M. E.; JOHNSON, C. N.. Amplified predation after fire suppresses rodent populations in Australia's tropical savannas. Wildlife Research, v.42, p.705716, 2016.

LIU, W.; WANG, L.; ZHOU, Y.; WANG, S.; ZHU, J.; WANG, F.. A comparison of forest fire burned area indices based on $\mathrm{HJ}$ satellite data. Nat. Hazards, v.81, p.971-980, 2016. DOI: http://doi.org/10.1007/s11069-015-2115-x

LOPES, A. C. L.; FREITAS, A. V. M.; COSTA, D. O.; BELTRÃO, N. E. S.; TAVARES, P. A.. Análise da distribuição de focos de calor no município de Novo Progresso-Pará. Revista Verde de Agroecologia e Desenvolvimento Sustentável, v.12, n.2, p.298-303, 2017. DOI: http://doi.org/10.18378/rvads.v12i2.4843

LOPES, I.; CARVALHO, A. A.; EDSON, J.; MORAIS, F.; SILVA, D. A.; LEAL, B. G.. Pluviometria, balanço hídrico e produtividade agrícola para regiões da Bahia e Tocantins. Revista Engenharia na Agricultura, Viçosa, v.27, n.3, p.257-271, 2019. DOI: http://doi.org/10.13083/reveng.v27i3.866

MALHEIROS, R.. A influência da sazonalidade na dinâmica da vida no Bioma Cerrado. Revista Brasileira de Climatologia, v.19, p.113-128, 2016. DOI:

http://dx.doi.org/10.5380/abclima.v19i0.48876

MMA. Ministério do Meio Ambiente. Plano de ação para prevenção e controle do desmatamento e das queimadas: cerrado. Brasília: MMA, 2011.

MMA. Ministério do Meio Ambiente. PP Cerrado: Plano de Ação para prevenção e controle do desmatamento e das queimadas no Cerrado: 2a fase (2014-2015). Brasília: MMA, 2014.

NARDINI, R. C.; CAMPOS, S.; RIBEIRO, F. L.; GOMES, L. N.; FELIPE, A. C.; CAMPOS, M.. Avaliação das áreas de conflito de uso em APP da microbacia do ribeirão Morro Grande. Caminhos de Geografia, Uberlândia, v.16, n.55, p.104-113, 2015.

OLIVEIRA, C. J.; CHAVES, H. M. L.. Tendências e Variabilidades nas Séries Históricas de Precipitação Mensal e Anual no Bioma Cerrado no Período 1977-2010. Rev. Bras. Meteorol., v.35, n.1, p.157-169, 2020. DOI: http://doi.org/10.1590/0102-7786351019

OLIVEIRA, U. C.; OLIVEIRA, P. S.. Mapas de Kernel como Subsídio à Gestão Ambiental: Análise dos Focos de Calor na Bacia Hidrográfica do Rio Acaraú, Ceará, nos Anos 2010 a 2015. Espaço Aberto, v.7, n.1, p.87-99, 2017. DOI: http://doi.org/10.36403/espacoaberto.2017.3473

PANTOJA, N. V.; SELHORST, D.; ROCHA, K. S.; LOPES, F. M. C.; VASCONCELOS, S. S.; BROWN, I. F.. Observações de queimadas no leste do Acre: subsídios para validação de focos de calor derivados de dados de satélites. Anais do Simpósio Brasileiro de Sensoriamento Remoto, v.12, p.3215-3222, 2005.

PANTOJA, N. V.; BROWN, I. F.. Acurácia dos sensores AVHRR, GOES e MODIS na detecção de incêndios florestais e queimadas a partir de observações aéreas no estado do Acre, Brasil. In: SIMPÓSIO BRASILEIRO DE SENSORIAMENTO REMOTO. Anais. 2007.

SALO, P.; KORPIMÄKI, E.; BANKS, P. B.; NORDSTRÖM, M.; DICKMAN, C. R.. Alien predators are more dangerous than native predators to prey populations. Proceedings of the Royal Society of London B: Biological Sciences, v.274, p.1237-1243, 2007. 
SANTOS, C. D.; CHAVES, M. L. J.. Difusão do agronegócio e urbanização no Nordeste: as regiões produtivas do agronegócio da soja no oeste da Bahia e da fruticultura no baixo curso do rio Açu/Jaguaribe (CE/RN). Geografia Ensino e Pesquisa, v.18, n.2, p.39-56, 2014. DOI: http://doi.org/10.5902/2236499413277

SANTOS, M.. A urbanização brasileira. 3 ed. São Paulo: Hucitec, 1996.

SOUZA, N. P.; SILVA, E. M. G. C.; TEIXEIRA, M. D.; LEITE, L. R.; REIS, A. A.; SOUZA, L. N.; ACERBI JUNIOR, F. W.; RESENDE, T. A.. Aplicação do estimador de densidade kernel em unidades de conservação na bacia do rio São Francisco para análise de focos de desmatamento e focos de calor. In: SIMPÓSIO BRASILEIRO DE SENSORIAMENTO REMOTO, 16. Anais. São José dos Campos: INPE, 2013. p.4958-4965.

STRASSBURG, B. B. N.; BROOKS, T.; FELTRAN-BARBIERI, R.; IRIBARREM, A.; CROUZEILLES, R.; LOYOLA, R.; LATAWIEC, A. E.; OLIVEIRA FILHO, F. J. B.; SCARAMUZZA, C. A. M.; SCARANO, F. R.; SOARES FILHO, B.; BALMFORD, A.. Moment of truth for the Cerrado hotspot. Nature Ecology e Evolution, v.1, n.99, 2017. DOI: http://doi.org/10.1038/s41559-017-0099
TOMZHINSKI, G. W.; COURA, P. H. F.; FERNANDES, M. C. Avaliação da detecção de focos de calor por sensoriamento remoto para o Parque Nacional do Itatiaia. Biodiversidade Brasileira, v.1, n.2, p. 201-211, 2011.

VACCHIANO, M. C.; SANTOS, J. W. C. M.; ANGEOLETTO, F.; SILVA, N. M.. Do data support claims that Brazil leads the world in environmental preservation?. Environmental Conservation, v.46, n.2, p.118-120, 2019. DOI: http://doi.org/10.1017/S0376892918000371

WHITE, B. L. A.; RIBEIRO, A. S.. Análise da precipitação e sua influência na ocorrência de incêndios florestais no Parque Nacional Serra de Itabaiana, Sergipe, Brasil. Ambi. Água, Taubaté, v.6, n.1, p.148-156, 2011. DOI: http://doi.org/10.4136/ambi-agua.180

ZYLSTRA, P.; BRADSTOCK, R. A.; BEDWARD, M.; PENMAN, T. D.; DOHERTY, M. D.; WEBER, R. O.; GILL, A. M.; CARY, G. J. Biophysical mechanistic modelling quantifies the effects of plant traits on fire severity: species, not surface fuel loads, determine flame dimensions in Eucalypt forests. Plos One, v.11, n.8, 2016. DOI: http://doi.org/10.1371/journal.pone.0160715

A CBPC - Companhia Brasileira de Produção Científica (CNPJ: 11.221.422/0001-03) detém os direitos materiais desta publicação. Os direitos referem-se à publicação do trabalho em qualquer parte do mundo, incluindo os direitos às renovações, expansões e disseminações da contribuição, bem como outros direitos subsidiários. Todos os trabalhos publicados eletronicamente poderão posteriormente ser publicados em coletâneas impressas sob coordenação da Sustenere Publishing, da Companhia Brasileira de Produção Científica e seus parceiros autorizados. Os (as) autores (as) preservam os direitos autorais, mas não têm permissão para a publicação da contribuição em outro meio, impresso ou digital, em português ou em tradução. 